\title{
El testimonio: reflexiones sobre su valor, formas y pertinencias en las ciencias sociales
}

\author{
Testimony: reflections on its value, forms and relevance \\ in the social sciences
}

Damir Galaz-Mandakovic ${ }^{3}$ damirgalaz@gmail.com

\section{Resumen}

El presente documento expone una aproximación teórica respecto al testimonio, analizando su valor, formas y pertinencias como fuente de información y archivo para las Ciencias Sociales, especialmente la Historia. Se enfatiza en sus modos de producción, valorización y usos para considerar la subjetividad, la diversidad discursiva, la heterogeneidad social y la descolonización ante los discursos magistrales.

\section{Palabras clave}

Testigos. Ciencias sociales - Investigaciones. Discursos. Memoria. Asociación de ideas. Pensamiento. Respuesta condicionada.

\section{Abstract}

This document shows a theoretical approximation in regards to testimony, analyzing its value, forms and relevance as a source of information and archive for the Social Sciences, especially History. It emphasizes its production modes, valuation, and uses in order to consider the subjectivity, discursive diversity, social heterogeneity and decolonization before master speeches.

\section{Keywords}

Witnesses. Social Sciences-Researches. Speeches. Memory. Idea associations. Thought. Conditioned Response.

Profesor de Historia y Geografía (Universidad de Tarapacá, 2007), magíster en Ciencias Sociales (Universidad de Antofagasta, 2011), magíster y doctor en Antropología (Universidad Católica del Norte de Chile, 2017), y doctor en Historia (Université Rennes 2, 2017). 


\section{Introducción}

La historia oral, con su potencia inevitable en la memoria social y en las Ciencias Sociales, ha generado espacios de debates epistemológicos y metodológicos. Tales discusiones se centran en los cambios que en los últimos años han acaecidos en los estudios históricos con la incorporación de la memoria colectiva mediante los sujetos que ofrecen testimonios (Mendoza et al, 2015:11). Dicho debate está centrado en si acaso se considera el testimonio como fuente y nueva forma de archivo social (Borderías, 1995).

Son múltiples las definiciones de testimonio, pero varias de ellas convergen en definirlo como un relato no ficcional que es narrado en primera persona por algún protagonista o testigo de algún hecho o proceso en particular (Skolodowska, 1992; Bordería, 1995; Castro, 2003; Aragón, 2011; Mendoza, 2015).

Podríamos decir que el testimonio es un discurso en primera persona sobre algo que resulta desconocido y que solo es accesible gracias al mismo testigo. En ese sentido, en los relatos del testigo se desemboca en una insistencia en la relación entre el saber y el poder que se entrelaza a partir del testimonio que puede ser comprendido como un nuevo modo de verdad (Foucault, 2005).

Esta discusión y teorización sobre el testimonio, que proponemos en este artículo, surge en el escenario de manifestación de ciertas miradas desdeñosas en la historiografía latinoamericana que inhiben y censuran la potencia del testimonio, desarrollándose, de ese modo, una reinauguración de las relaciones coloniales y la exclusión de grupos subalternos, populares o étnicos. ${ }^{2}$

\section{Quién es el testigo}

Etimológicamente, la palabra testigo remite a los registros romanos, pueblo en donde se tenía por costumbre jurar llevando alguna de las manos a las gónadas, con pleno convencimiento de que, si llegaban a jurar en falso, los dioses iban castigar enviándoles impotencia y esterilidad. Esta costumbre habría dado origen a varias palabras cuya etimología sería la locución testis: testimonio, testificar, testamento y testículos (Velis-Mesa, 2008, p. 190). Con base en esta versión falogocéntrica, podemos decir que testimoniar vendría siendo un "acto de hombría", donde estaba en juego el valor de la persona mediado por cierta penitencia divina.

Otras versiones nos hablan que la palabra testigo posee dos raíces. En primer lugar, testis, aquel que como 'tercero' -terstis- asiste a un proceso entre dos. Testigo sería quien en calidad de espectador da cuenta de unos hechos o procesos (Aragón, 2011, p. 298). En este tenor, el tema de la presencialidad es central, porque desde ahí adquiere su carácter de validez, debido a que el testigo califica para testificar. Es decir, para contar lo que vio, escuchó, cruzándose muchas veces el actor con el testigo. El actor, de todas maneras, también testifica. En ese cruce, es posible hallar otros nombres dirigidos al testigo, como superstes, que vendría siendo superviviente (Gómez de Silva, 1988). En este caso se trata de quien ha vivenciado algunos episodios de los que puede informar. Por ello, el superviviente, a diferencia del testigo, no relata o no refiere como asistente algunos hechos ajenos a él. Vendría siendo él mismo quien los ha experimentado, siendo este el motivo de calificación para comunicarlo. Este motivo de supervivencia, este sobrevivir del testigo, lo instala en relación con el testamento, este como depositario de una vivencia personal, de la cual se presenta como heredero, guardián o garante de una herencia tomada (Aragón, 2011, p. 198).

Según Aragón, a la hora de hablar de los riesgos del declarante, indica que la palabra del testigo exige como condición de existencia radicando su propia imposibilidad. Pero antes de ello, existe el perjurio y la mentira como asedios al testimonio, elementos que lo ponen en cuestión. Todo discurso que intente aislar un contenido propio en el testimonio estará condenado a la pérdida. En una escena

\footnotetext{
2 Nos referimos especialmente a las historiografías nacionalistas, clasistas, conservadoras, confesionales e ideológicamente militantes de las derechas en Latinoamérica, quienes trabajan con especial énfasis las historias de las dictaduras omitiendo pasajes de violencia, cuestionando, además, los procesos de reivindicaciones étnicas en su dimensión territorial y política. Un caso notable de este tipo de historiografía nos remite al historiador Gonzalo Rojas, Alfredo Jocelyn-Holt y Sergio Villalobos en Chile; Carlos D. Mesa en Bolivia, además de la reivindicación universitaria y clasista de algunos autores conservadores bolivianos, tales como Alcides Arguedas, Gabriel René Moreno, Enrique Finot y Manuel Enrique Paredes, entre otros historiadores de estudios coloniales que evidencian una sospechosa "imparcialidad" o los mismos trabajos del filósofo H.F. Mansilla, los cuales han sido considerados como una apología a las relaciones coloniales. Asimismo, la hegemonía escolar de los textos de Ibáñez y Fraga, en Argentina, remiten a la reivindicación de cierto conservadurismo y elitismo. (Para el caso del racismo historiográfico en Brasil, ver: Ledezma, G. [2017]. "Racismo o colonialidad del saber en la historiografía brasileña, de Francisco Varnhagen a Gilberto Freyre". Dossier Religación. Revista de Ciencias Sociales y Humanidades, Vol II, № 5.)
} 
donde los límites no sean tan nítidos como podríamos esperar y en la que la frontera entre estos sea permeable, transitable o porosa, supone que debemos hacer un esfuerzo por diferenciar o desigualar teóricamente entre cada uno de los términos (2011:200).

\section{El testimonio y sus posibilidades}

El testimonio es fruto de una experiencia personal que conecta cierta intimidad; y es fruto de la observación o vivencia en primera persona de algún hecho, proceso o fenómeno. El testimonio se torna relevante por la intimidad, en cuanto a secreto que deja de serlo, a por la privacidad y parcialidad de la experiencia. No obstante, en estas consideraciones, el tema de la verdad, en cuanto a sus verdades fruto de la experiencia específica, adquiere el carácter de particularidad. Sin embargo, ¿en qué medida la ciencia, en sus búsquedas generalizantes y universalizantes chocan con lo subjetivo, con lo experiencial, con lo particular, con lo parcial? ¿Cómo podemos situar al testimonio en esa trama y cómo lo situamos en la investigación para construir conocimiento?

Lo interesante es situar, aún en el monopolio del logos, al testigo; a saber que el testigo muchas veces es acusado de incorporar un discurso "parcial". Su incorporación debe ser efectiva a saber de la propia descalificación que ejercen esas búsquedas generalizantes y totalizadoras de las ciencias, que, tal como acusó Derrida, la ciencia es el lugar del dominio absoluto: "El proyecto del saber absoluto (...) es la verdad del proyecto filosófico" (Derrida, 1992, p. 149).

En ese marco, es pertinente e interesante sacudir epistemológicamente a la ciencia, deconstruirla, siendo necesario cuestionar siempre las ideas sobre la verdad, realidad o autenticidad. Quizás esos parámetros han determinado, en el campo del dominio impuesto por el monopolio de la verdad, el surgimiento de la crítica tenaz hacia la Etnografía por su condición de subjetiva y particularmente localizada (Vargas-Jiménez, 2016).
Consideramos que la Etnografía, y los testimonios surgidos en ella, no disminuyen su valor a la hora de incorporarlos en la investigación. Porque cuando hablamos de la incorporación de la subjetividad, se nos representa una situación de convergencia de diversos planos de realidad que nos obliga a analizar el recorte de la observación del fenómeno, para dar cuenta de su condición producente. Es por tales razones que la discusión se manifiesta contra la tendencia a reducir la parcialidad y definir al sujeto como un mero producto histórico (Zemelman, 2005, p. 84).

Con esta incorporación, que contiene al sujeto como parte de su propio discurso y proceso de construcción de conocimiento, como un actor, es pertinente recuperarlo desde sus diversas facultades, ya sean emocionales o con sus propias imágenes, imaginaciones e imaginarios, y también con la intuición. Al recuperarlo en esa integralidad, nos centramos en la consideración holística tan reivindicada por Hugo Zemelman (2005, pp. 81-82).

Por ello, es oportuno que no solo se explique sino que potencie su propia construcción y lo contextualice y lo articule históricamente, ampliando la subjetividad y las posibilidades de conocimiento con el propósito de ver su realidad con más de una posibilidad en una realidad polisémica y multivariada. Es allí en donde el testigo se vuelve un actor central y una fuente que se ha de considerar. ${ }^{3}$

Se suma a este enfoque lo planteado por Menéndez en cuanto a que la recuperación del testimonio es una "aproximación cualitativa junto con el énfasis en lo holístico, en lo local, en lo simbólico, (en) el punto de vista del Otro" (Menéndez, 2011, p. 10).

Consideramos que la conciencia histórica, al ser una de las formas de la subjetividad, también es una constelación que además de comprender la cognición articula a la voluntad y la afectividad del investigador.

\footnotetext{
El testimonio ha sido considerado por importantes escuelas de investigación social, al grado que algunos lo han denominado como la Nouvelle Histoire (Nueva Historia), corriente historiográfica puesta en marcha por Jacques Le Goff y Pierre Nora en los años 1970 como parte de la Escuela de los Annales francesa. Otros importantes antecedentes nos remiten a los trabajos de Paul Thompson y Ronald Blythe en Inglaterra. En España, los trabajos sobre la realidad de los obreros durante el siglo XX también han considerado a la oralidad como base sustancial, como así también a la realidad del franquismo. Mención aparte merecen los trabajos de la llamada Escuela de Chicago en EE.UU.; igualmente los trabajos que se desarrollan en Argentina con la creación del Instituto de Historia Oral en Buenos Aires, además del centro "Otras memorias"; en Venezuela emergió la Asociación Venezolana de Historia Oral. Destacado trabajo también ha realizado la Red Latinoamericana de Historia Oral como espacio académico de articulación, intercambio y difusión de la investigación que se realiza en diversos países de América Latina sobre la historia del presente, basada tanto en las fuentes tradicionales de la historia como así también en la memoria oral de los pueblos.
} 
La incorporación de estos discursos tiene espacios de indeterminación; ahí radican las potencialidades, de modo que no pueda ser reducida a la conciencia teórica, a la cual apela la ciencia universalizante y totalizadora. La teoría y la explicación contenida en ella son aspectos cristalizados del pensamiento que se adscriben solo a lo dado. Con la incorporación de la subjetividad, renovamos planos de la complejidad. Y esta articulación nos aporta una nueva construcción de conocimiento más allá de la conciencia teórica. En definitiva, cuando se cuestiona a la discursividad testimonial por su "subjetividad", se está cuestionando la articulación que se realiza entre tiempo y espacio; entre el sujeto y sus actos mentados y no mentados, es decir a la expresionalidad de los cronotopos (Carroll, 1983).

La incorporación del testimonio nos puede ofrecer la posibilidad de obtener resultados desde un carácter inductivo y no nomotético. Por tales razones, los estudios sociales poseen un carácter polivalente. En ese sentido, se rechaza la afirmación del monismo causal y el monismo metodológico como enfoque de investigación (Geertz, 1992; Horkheimer, 2003).

La oportunidad que se nos brinda va por la consideración de la diversidad de los sujetos, hechos y procesos particulares que no se atienen solo a lo dado. El mundo social ya no debería estar sujeto a leyes invariables. La razón ya no debería basarse exclusivamente en quien observa desde alguna exterioridad, ni tampoco debe determinarse a aprehender solo de lo "visible", de lo unidimensional, sino de lo problematizado. En esta lógica, el mundo social y los resultados que podemos aprehender no tendrían la razón de ser predecibles ni determinados; como en el positivismo se han aplicado las leyes de la naturaleza, no considera, aunque parezca asombroso, los aspectos humanos en el estudio social. Es decir, las emocionalidades ni los sentidos, ni mucho menos los símbolos, ni los aspectos propios de alguna forma de etnicidad. Se niega, por tales razones, las únicas formas de legitimidad que representan la referencia empírica del positivismo, tal como lo expuso Geertz al proponer la descripción densa. La negación del otro es la operación densa para articular la colonialidad en las relaciones sociales; y la explicación del otro desde prismas etnocéntricos.

En el decir de Zemelman, el discurso teórico y nomotético atrapa, por tal razón considera que el pensamiento epistémico es pre-teórico, porque busca resolver la relación del pensamiento con la realidad que se intenta nombrar y desde ahí construir conocimiento $(2005$, p. 82).

El valor del pensamiento epistémico debe surgir cuando ayuda a redefinir las problematizaciones y construir objetos nuevos, para nombrar de nuevo, para reconocer nuevas formas de inscripción y de archivo. A su vez debe problematizar rompiendo lo dado, lo establecido, ayudando a construir conocimiento crítico. Asimismo, cuando establece relaciones sujeto a sujeto.

En la conformación de esta narrativa, detectamos una tendencia al bricolaje, en el sentido de que con el testimonio como archivo surge una reflexión con un conjunto de objetos, sujetos y relaciones que ofrecen nuevos significados. Testimoniar es un trabajo con signos dentro de una historicidad. Es decir, estos actos de testimonio pueden ser entendidos como un operador de la transformación de lo estructuralmente dado o dicho.

Hablamos de una práctica de bricolaje porque se trabaja con lo vivido, con lo secundario, con desechos de acontecimientos. En ese sentido, la sincronía predomina sobre la diacronía. Quizás, se articula la estructura y la anécdota. O quizás este tipo de voz busca compensar una situación desfavorable, de dominación, en expresión de una asimetría estructural. Sus sentidos se explicarían en el devenir de sus vidas, pero entendido este devenir como fruto de un poder, entendido el poder como un diferencial, porque habrían dos fuerzas operando, lo contado y no lo contado.

\section{Cómo podemos valorar el testimonio}

El testimonio es relevante en cuanto a proporcionar información que conecta la intimidad de un proceso personal hacia la proyección de un proceso colectivo. Ofrece la posibilidad de hallar diversas versiones que dan cuenta de la heterogeneidad de los hechos o procesos. Usualmente es una multifonía que se resiste a la unidad.

Austin mencionó que los tipos de enunciados ofrecen las posibilidades para valorar en un nivel constatativos 0 performativos. Los primeros dan las señales para describir determinadas cosas; con lo segundo, no se constata o describe nada sino que se realiza un acto (1982, p. 430).

Muchas veces es el carácter performativo el que otorga valoración al testimonio, en el sentido de que la 
performatividad trasforma la verdad en un hecho, en un testimonio obrado. Lo propio del testimonio no está en la verdad expuesta, cuya exposición al posible error o equivocación no se puede excluir de antemano; no está en lo que se dice, en el contenido objetivo, que a su vez está viciado de subjetividad, sino en lo que se hace al decir, en lo que acompaña, esto es, en el compromiso que adquiere el testigo al contar su verdad (Aragón, 2011, p. 303). Desde ahí, incluso, muchas veces es posible conectar el testimonio y la confesión en cuanto a un "hacerse la verdad", que en la lógica de Austin (1982) es el accesorio en lo dicho y lo nodicho. Entonces, la verdad no es lo dicho, sino que mediante la palabra se hace la verdad, incluyendo los elementos de los actos del habla más el paralenguaje que expresa accesoriamente nuevos contenidos, confirmando o no por medio de dispositivos semióticos (Lazzarato, 2012). Porque el que testimonia sitúa su palabra y con ello su credibilidad, su persona y el valor social de su existencia en una realidad comprometida con la verdad, pidiendo a su vez confianza y creencia en lo dicho.

Jacques Derrida (1999) deposita en el carácter secreto, a su vez privativo de la verdad obtenida en el testimonio, el tema de la creencia, por ello dice que testimoniar es un acto de fe. Desde ahí, la validez del testimonio llega hasta el punto en que deja de sostenerse, derivando el surgimiento de la mentira. Lo difícil es poder generalizar cuándo surge. Porque, obviamente, todo testimonio es un mundo en sí mismo, es un microcosmos de experiencias y verdades. El testimonio posee la particularidad de lo que solamente puede ser creído, de lo que, tras pasar la prueba, la indicación, la constatación, el saber, apela únicamente a la creencia, por lo tanto, a la palabra dada (Derrida, 1997).

En relación con el presente y la verdad, Foucault nos dice: "En esta verdad que es, de algún modo, completa y total, en la que todo ha sido dicho, falta algo que es la dimensión del presente, la actualidad, la designación de alguien. Falta el testigo de lo que realmente ha ocurrido" (Foucault, 2005, p. 44). Es decir, se necesita ahora el presente y el testigo del pasado: el testigo de lo que realmente sucedió.

\section{Cuál es la aporía del testimonio}

Considerando la creencia como base primordial, a la hora de escuchar un testimonio, no basta solo su carácter "creíble"; es ahí cuando surge la aporía, cuando el testimonio se valida a sí mismo con base en lo increíble o lo imposible (Aragón,
2011, p. 304). Derrida señaló que no podemos testimoniar más que de lo increíble: "De lo que puede solamente ser creído, de lo que, al exceder la prueba, la indicación, la constatación, el saber, apela solamente a la creencia, por lo tanto, a la palabra dada" (Derrida, 1997, p. 41).

El testimonio debe exceder el marco de lo posible para abrirnos a un pensamiento de lo imposible; posible en tanto que imposible: im-posible. Según esto, cuando alguien da un testimonio, aquello que es creíble, verosímil, aceptable, coherente o asumible, en definitiva, posible, no está testimoniando en sentido radical. Por ello, testimoniar sería solo de lo intestimoniable (Aragón, 2011, p. 304). Un testimonio tiene que ser extraordinario; que se acepte como un acto de fe. No hay testimonio que no sea inaudito o insólito como un acontecimiento. Necesariamente el testimonio se basa en la creencia o en la confianza del informante, el cual será relevante y trascendente cuando, a pesar de la ausencia de pruebas, el carácter de increíble será lo elemental para construir un relato. La prueba o la evidencia es un demostrar, que es performativo en propiedad, que no requiere el accesorio de un relato que, de pronto, lo puede complementar o contextualizar; pero al ser así, deja de ser prueba y se transforma en testimonio en sí mismo. Aquí se instala el tema de la creencia, muy bien explicado por Derrida (1999), quien nos dice: "La creencia por excelencia, que no es posible más que creer en lo imposible. El milagro sería del orden de la pura creencia" (Derrida, 1999, p. 147).

El testimonio, entonces, se valida por lo increíble y se vale por lo intestimoniable en el marco de la verosimilitud. Creer lo increíble, por el solo hecho de la creencia. Curiosamente la imposibilidad hace al testimonio (Derrida, 1999), y un carácter de verdad inimaginable; es decir, la verdad irreductible a los elementos reales que la constituyen es, en rigor, la misma aporía del conocimiento histórico: la no coincidencia entre hechos y verdad, entre comprobación y comprensión. En esa dirección, se plantea lo necesario que es una ética del testimonio, que en ciertas ocasiones está en tensión con la ética del dominio, con la ética oficial y predominante, con los programas de conformación, a modo de ortogramas, de los dispositivos de regulación y control de operación (Agamben, 1999).

Por otra parte, el análisis debe encontrar las claves de comprensión que se sitúan en los límites del lenguaje mismo, en la expresión de otra aporía más profunda y compleja en el testimonio, en la que este remite a lo intestimoniado y 
se define como el encuentro de dos imposibilidades, la de referir y narrar la experiencia y la de testimoniar por quien no tiene lengua (Sorgentini, 2002, p. 255). Porque, en ese sentido, según nuestras estructuras y ortogramas, no existe lo que no está afuera del lenguaje: "Se atestigua el manifestarse de una potencia de decir solamente por medio de una impotencia, lo que hace que su autoridad no dependa de una verdad factual, de la conformidad entre lo dicho y los hechos, entre la memoria y lo acaecido, sino de la relación inmemorial entre lo indecible y lo decible, entre el dentro y el fuera de la lengua" (Agamben, 1999, p. 165).

Si bien la biografía ha sido considerada como dispositivo de control de la vida por parte de Foucault, además de ver el archivo como un conjunto de formulación de enunciados que luego constituyen una epistemia, Agamben (1999) ha dicho que el archivo es la lengua y lo dicho en dicha lengua. Entendiendo que el corpus sería lo ya dicho. Lo no semántico sería la reunión de lo no dicho y lo decible.

El lenguaje, según Carroll, deviene en una cárcel: todo lo "posible" está dentro del lenguaje. Y lo que está afuera de él "no existiría" (1983, p. 69). El lenguaje es construido por la Dialéctica y la Historia; contra eso se propone la fundación de la comunidad social en relación de sí mismo con el otro, con la alteridad. El lenguaje debemos verlo como diálogo, abordar el origen y el contexto, más que el adentro y el afuera, la relación entre la forma del discurso más que lo extrínseco e intrínseco (Carroll, 1983). Es el mal del estructuralismo, que ve el lenguaje como fórmula abstracta. Trabajando como si la lengua fuese muerta, sin dinámica, sin creación ni actividad. Porque el diálogo permite que el lenguaje adquiera vida. "Los cadáveres de la lengua" producen identidades formales; es una dimensión cadavérica. No otorga vitalidad, porque asume la lengua como un dispositivo cosificado y cerrado (Carroll, 1983, p. 69). Oportuno es, entonces, captar el discurso referido como aquel discurso dentro del discurso. Al hablar, se incorpora un contexto dentro de otro. El discurso se construye en la relación, si no, deviene el monólogo y la colonización del otro (Carroll, 1983, p. 81).

En ese escenario, cada investigador social debe deconstruir los discursos dogmáticos y las imposiciones hegemónicas del llamado contexto o sentido preestablecido. Porque despersonaliza y establece barreras entre el autor y el otro. Asimismo, quien investiga debe indagar cuándo la palabra es compartida con alguien, para identificar las ventriloquías 0 cuando la voz se pierde en otras voces; a saber que la voz es fruto de un conflicto de voces, surgiendo allí la multivocalidad. Pertinente y precisa es la práctica de la heteroglosia, que permite recuperar discursos desde el otro. Es la cita de otros discursos para hacer otros discursos (Carroll, 1983, pp. 78-79).

\section{Comentarios finales: singularidad, memoria y archivo}

Consideramos que la particularidad del testimonio radica y se centra en su singularidad. Es privado, pero es también contable e irremplazable. Pero esa misma singularidad debe ser repetida, quizás para probar la firmeza de lo dicho y de lo no dicho.

Arango advierte que, junto a la singularidad y universalidad, "el testimonio es irreductible a la ficción, al simulacro o a la mentira; no obstante, un testimonio que no pudiera verse afectado por la mala fe, del que se supiera sin género de sospecha de su veracidad, se perdería como testimonio. Lo que constituye una amenaza" (Aragón, 2011, p. 307).

La creencia establecida entre el que testimonia y el que escucha es una confianza de carácter inaugural; hay una promesa admitida en cada acto de palabra. Es una confianza en lo que se dice, que puede ser tomada sin dogmas (Derrida, 1998). Se nos ofrece, entonces, la posibilidad de ir desintegrando la noción de centro, como así también la de orden, jerarquía, y se inicia un novísimo trabajo sobre los márgenes, las fronteras, las periferias, las 'minorías': y lo periférico puede ser observado centralmente (Sklodowska, 1992, p. 88).

Por ello, el testimonio ofrece un carácter transgresor en potencia con lo oficial, con los discursos maestros. Porque en ciertas ocasiones se va contra el consentimiento espontáneo dado por las grandes masas de la población, dado por los grupos dominantes. No obstante, la voz de quien nos da testimonio es "darle voz a quienes participan en la historia sin participar en su interpretación" (Sklodowska, 1992, p. 68). Aunque debemos indicar que en ciertos casos hay una oficialización de los testimonios o hay testimonios que devienen en discursos maestros.

Lo interesante es establecer una diferencia entre los testimonios mediatos y los testimonios no-mediatos. Los mediatos serían los novelizados y el testimonio etnográfico o sociohistórico, y en parte, también, las novelas testimoniales. A su vez, los testimonios no-mediatos serían 
los legales, el diario, las memorias y la autobiografía. En esa escena, surge la categoría de "escritura de la voz" para aludir al testimonio; con ello podemos concebirlo como una elaboración discursiva problemática frente a la narración del otro, dejando en claro que hay dos sujetos a la hora de leer: el que narra su historia y el que la escribió (Sklodowska, 1992, p. 82). Otorgar espacios a los testimonios de los afectados en la escritura de la historia es una reivindicación de las voces del lado oprimido (Richard, 2007); compone un acto contra-hegemónico que refuta las representaciones e inscripciones totalizantes y englobantes. El testimonio introduce una crítica "a la monumentalidad heroica de las verdades mayúsculas" (Richard, 2007, p. 122).

El testimonio se sustenta en la memoria. ${ }^{4}$ Sin embargo, las relaciones entre memoria y olvido en el psicoanálisis no son de oposición (Freud, 1996). Los olvidos diarios, por muy triviales que sean, son la expresión de otro mensaje, pero que se expresa mediante un disfraz insistente. En ellos surge la expresión de una transacción entre lo que se quiere olvidar: lo reprimido y la defensa que se opone contra ello. La represión, siendo una tentativa de olvido, es la forma más lograda de persistencia de la memoria; lleva en su seno la potencia del retorno de lo reprimido por las vías más dolorosas del conflicto.

Lo que retorna a la memoria es eso que 'desubjetivó' al sujeto, que produjo su destitución subjetiva; el encuentro que lo dejó reducido a aquello que se denomina la nuda vida. Por ello, se torna necesario en un pedir historia, porque se reclama dar cuenta de un proceso de 'desubjetivación' que lo instituyó, de la vinculación con lo perdido, que además configura la relación con los otros. En el decir de Agamben, es la expresión del no-hombre (1999, p. 142). O sea, el hombre es, como tal, en la medida en que dan testimonio del no-hombre. Desde ahí se comprende que, en el sujeto que proporciona un testimonio de él mismo, hay siempre una escisión o una interrupción que lo constituye. Esta interrupción o escisión se plantea entre el viviente y el hablante, entre la vida y el logos, entre el sentido y el sinsentido, y en la articulación entre imposibilidad y posibilidad de decir. El sujeto del testimonio está constitutivamente escindido: "No tiene otra consistencia que la que le dan esa desconexión y esa separación y, sin embargo, no es reductible a ellas" (Agamben, 1999, p.158).

El testimonio otorga la posibilidad de ocurrencia. El corte emerge en la lengua misma mediante dos movimientos: el testigo habla por los que no pueden hablar, por los operadores de la subjetivación, que sería la posibilidad del decir; y la contingencia (condiciones del acto y lo que pueda ocurrir en ese acto). Por otro lado, están los operadores de la desubjetivación: la imposibilidad de decir, el lenguaje no lo permite o el contexto. Además de la necesidad como límite de lo que se puede o no se puede. Frente a todo ello, el testimonio se constituye con un gran valor: que es ofrecer una memoria y un nuevo archivo para las Ciencias Sociales.

Elvalory la pertinencia del testimonio resultan fundamentales como fuentes en el contexto latinoamericano. Por ejemplo, considerando los procesos de tiranías cívicas y militares que llevaron a múltiples acciones de facto, que no quedaron registradas documentalmente por razones de seguridad estatal y por los deseos de invisibilizar la violencia, por ejemplo, mediante la destrucción de archivos documentales. Por otra parte, los procesos de reetnificación, la emergencia de procesos de reivindicación de lo indígena y la revalorización de los grupos étnicos que sustentan en sus memorias y relatos orales contenidos y saberes que entregan nuevas luces de comprensión y relación social interétnicas, brindando la posibilidad de producir problematizaciones de nuevas temáticas de investigación, adicionándose la memoria, identidad y los relatos de los grupos subalternos y grupos populares que han sido colonizados en procesos extractivistas; $y$ otros que han sido marginados de las "grandes historias".

\section{Referencias}

Agamben, G. (1999). Lo que queda de Auschwitz: El archivo y el testigo. Homo Sacer III. Valencia: Pre-Textos.

Aragón González, L. (2011). El testimonio y sus aporías. Escritura e imagen. (7), 295-311.

Austin, J. (1982). Cómo hacer cosas con palabras: Palabras y acciones (How to do things with words). Barcelona: Paidós.

\footnotetext{
4 Para Freud (1996), el inconsciente está constituido por huellas mnémicas, es decir, por un conjunto de imágenes, sonidos, etc., que además están asociados con palabras, frases que poseerían una semántica propia y también con una conexión a un circuito emocional determinado. Esto determina la cualidad afectiva del recuerdo. Se constituyen, de este modo, múltiples formas variadas de inscripción que obedecen a la compulsión, a la repetición, a lógicas distintas que están sujetas a constantes transliteraciones.
} 
Borderías, C. (1995). La historia oral en España a mediados de los noventas. Historia y fuente oral. (13), pp. 11-27.

Carroll, D. (1983). The alterity of discourse: Form, History, and the question of the political in M. M. Bakhtin. Diacritics. Recuperado de www.jstor.org/stable/464660

Castro, F. (2003). Aprender investigando con fuentes orales. Revista de la Red de Cualificación de Educadores. 2 (14), 1-9.

Derrida, J. (1992). Points de suspension. Entretiens. Paris: Galilée.

Derrida, J. (1997). El Monolingüismo del otro, o la prótesis de origen. Buenos Aires: Manantial.

Derrida, J. (1998). De la gramatología. México, D.F.: Siglo XXI.

Derrida, J. (1998). De la gramatología. Recuperado de http:// jacquesderrida.com.ar.

Derrida, J. (1999). La contre-allée (con C. Malabou). Paris: La Quinzaine littéraire-Louis Vuitton.

Foucault, M. (2005). La verdad y las instituciones jurídicas. Barcelona: Ediciones Gedisa.

Freud, S. (1996). Psicopatología de la vida cotidiana. Madrid: Alianza.

Geertz, C. (1992). La Interpretación de las culturas. Barcelona: Gedisa.

Horkheimer, M. (2003). Teoría crítica. Madrid: Amorrortu.

Lazzarato, M. (2012). El funcionamiento de los signos y de las semióticas en el capitalismo contemporáneo. Revista Palabra Clave. (15), 713-725.
Mendoza, J. N., Beltrán, H., \& Vázquez, S. (2015). Estudio comparado del papel de las fuentes orales en la profesionalización de los historiadores. Revista Universidad y Sociedad. 7(3), 12-18. Recuperado de http://rus.ucf.edu.cu/

Menéndez, E. (2011). Técnicas cualitativas, problematización de la realidad y mercado de saberes. Cuadernos de antropología Social No 13. 9-51. Universidad de Buenos Aires.

Richard, N. (2007). Fracturas de la memoria. Buenos Aires: Siglo XXI.

Sklodowska, E. (1992). Testimonio Hispanoamericano: historia, teoría y poética. (62-97). New York: Peter Lang Publishing.

Sorgentini, H. A. (2002). Agamben, Giorgio, (2000) Lo que queda de Auschwitz. El archivo y el testigo. Horno Sacer III. (253-261). Recuperado de http://www.memoria. fahce.unlp.edu.ar/art_revistas/pr.3829/pr.3829.pdf

Vargas-Jiménez, L. (2016). ¿Cómo se concibe la etnografía crítica dentro la investigación educativa?

Revista electrónica Educare. 1-13.

Velis-Mesa, H. (2008). Palabras con historias. (4 ed.). Santiago de Chile: Ediciones Cerro Huelen.

Zemelman, H. (2005). Sujeto y sentido: consideraciones sobre la vinculación del sujeto con el conocimiento que construye. Voluntad de conocer. El sujeto y su pensamiento en el paradigma crítico. (81-94). Barcelona: Anthropos. 